\title{
Geographical variation in hospital admission rates: an analysis of workload in the Oxford region, England
}

\author{
John N Newton, Valerie Seagroatt, Michael Goldacre
}

\begin{abstract}
Objective - To measure variation in hospital admission rates between health districts in part of the English NHS, comparing a wide range of medical and surgical conditions.

Design - Retrospective analysis of interdistrict variation using linked routine hospital admission data. Comparisons were also made with levels of variation reported from the USA.
\end{abstract}

Setting - Oxford Regional Health Authority, 1979-86.

Subjects - Six district health authorities - total study population $2 \cdot 1$ million people, $1 \cdot 6$ million hospital admissions.

Main measures - Age and sex standardised hospital admission rates for resident populations for individual operations and diagnoses; systematic components of variation (SCV).

Results - Of 118 standard operation groups, 38 ( $26 \%$ of surgical workload) showed high variation (SCV 16 or more) and 40 (36\% of surgical workload) showed low variation $(\mathrm{SCV}<4)$. Operations (SCV) with very low levels of variation included prostatectomy $(0 \cdot 1)$, inguinal herniorraphy $(0.9)$, and cholecystectomy $(1 \cdot 3)$. Rates were more variable for myringotomy $(3 \cdot 7)$, hysterectomy $(4 \cdot 3)$, dilatation and curettage (5.6), and tonsillectomy $(6 \cdot 2)$. The SCV was high for only four of the 40 commonest medical causes of admission, and was low for 18 of them.

Conclusions - Most admissions in the Oxford region were for conditions that did not show a great deal of variation in admission rates. The level of variation for many surgical procedures was less than that reported in studies from the USA. Variation was no greater for medical causes of admission than for surgical conditions. Large scale variation may not be an inevitable consequence of autonomous clinical practice.

\section{(f Epidemiol Community Health 1994;48:590-595)}

Large differences have been found in recorded hospital admission rates between industrialised countries and areas within these. ${ }^{1-8}$ Although the causes of these differences are not fully understood they are not explained by differences in morbidity alone. ${ }^{39}$ For some con- ditions, variation may reflect clinical uncertainty about the need for treatment and this has been taken as evidence that the scientific basis of medical practice is inadequate or underused. ${ }^{10}$ The distribution of resources for hospital care is also a factor as undertreatment is likely in areas where people have limited access to health care while supplier induced demand probably results in overtreatment in other areas. ${ }^{11}$

Studies of variations in the UK have generally been based on data for a relatively small number of conditions. ${ }^{468}$ Reported levels of variation are known to differ widely from condition to condition. ${ }^{3}$ Without more comprehensive data it is difficult to assess the importance of conditions that show high variation as a proportion of overall workload. Although some of the early, now classic, studies in this area were British, ${ }^{12}$ many of the recent studies of geographical variation in the use of hospital beds have been performed on data from the USA. ${ }^{5}$ Even in the USA, however, the bulk of the research on variations has considered only seven surgical procedures (hysterectomy, tonsillectomy, cholecystectomy, appendicectomy, hernia repair, prostatectomy, haemorrhoidectomy). ${ }^{5}$ Also, it cannot be assumed that the degree of variation found in American studies necessarily exists in the UK because of the many important differences in the way hospital care is provided in the two countries. ${ }^{1213}$ Medical causes of hospital admission have been relatively neglected compared with surgical ones in studies of variation on both sides of the Atlantic, possibly because of the lack of suitable data. ${ }^{7}$

This study was undertaken to investigate variation in admission rates in a region of the English National Health Service (NHS) by analysing hospitalisation rates for the full range of operations and diagnoses at the level of district health authority populations. At this level of aggregation, differences resulting from variation in clinical practice should be most apparent. ${ }^{14} \mathrm{~A}$ small number of specialists work relatively autonomously in each district and the resources available to them tend to be similar within one regional health authority. Although the districts in our study are relatively few, wide variation has been described by others within a single region for a number of conditions. ${ }^{346}$ Our aim was to identify conditions which showed substantial levels of variation and those that did not. The proportion of surgical admissions that were for procedures which showed high levels of variation could also be estimated. 
Methods

THE DATASET

The data used were from the Oxford Record Linkage Study (ORLS) and consisted of routinely collected abstracts of records of all episodes of hospital inpatient care (including day cases but excluding outpatients) in six districts of the Oxford region (total study population $2 \cdot 1$ million; district populations from 249000 to 516000 people). We examined data on all admissions, including day cases, to general hospitals (that is, excluding psychiatric and maternity care) from 1979, when the ninth revision of the International Classification of Diseases (ICD9) ${ }^{15}$ was introduced, to 1986 (inclusive) when management of data collection was devolved to individual hospitals. The ORLS dataset provided both the Hospital Activity Analysis (HAA) system for the six districts and the one in 10 sample of it for the national Hospital Inpatient Enquiry (HIPE). It can be regarded as equivalent to that used for the HAA and HIPE elsewhere in England, except that the ORLS data are linked.

In this period, data collection was directed by one of us (MG). The staff responsible for data collection and coding were funded, trained, supervised, and monitored centrally, although, in most cases, they were sited physically within the hospitals. Completeness of data collection was monitored as a routine. Incomplete records and records which failed edit checks were returned for completion or correction. Samples of individual coders' coding were regularly checked for accuracy.

The ORLS included data for residents of the six districts admitted anywhere in the study area. Information on admissions for residents that occurred outside the ORLS area - approximately $5 \%$ overall - was sought by obtaining and analysing the national HIPE tapes for 1979-85 (HIPE stopped in 1985). We estimated, for residents of each district, the proportion of admissions which occurred outside the ORLS area for each procedure or diagnosis. Because of the different nature of the two datasets the HIPE information was used to interpret rather than adjust the rates derived from the ORLS.

\section{STATISTICAL METHODS}

We calculated indirectly age and sex standardised admission rates for resident populations of the six districts, wherever treated within the ORLS area, using admission rates in the total population as the standard. All admissions, including multiple admissions for the same person, were counted as separate episodes when calculating annual episode based admission rates. To calculate average annual person based rates, each person was counted once only for each condition for which he/she had been admitted in each calendar year, regardless of the number of times the person had been admitted. Both sets of rates were calculated for each diagnosis and procedure. The distinction between counts of people admitted and episodes of care is particularly important when considering admissions for chronic medical conditions.
The amount of variation between district admission rates was assessed by calculating the systematic component of variation (SCV). ${ }^{3}$ The SCV is the variance of the ratios of observed to expected admission rates, excluding the random component due to Poisson variability. By convention, the SCV is multiplied by 100 . The value of the SCV is independent of the number of areas compared, although the precision with which it is estimated does depend on this number. A high SCV value indicates a large amount of interdistrict variation. We allocated operations to eight categories from low to high levels of variation according to the value of the SCV. The proportion of surgical workload accounted for by operations in each category of variability was also calculated. These proportions could be compared directly with similar data reported from the USA by Wennberg et al. $^{16}$

\section{DEFINING CAUSES OF ADMISSION}

Admission rates were calculated for all surgical procedures, except those related to childbirth, grouped into 118 standard English groups. ${ }^{17}$ For a small number of procedures the standard Office of Population Censuses and Surveys (OPCS) groups were thought to be insufficiently robust for our purpose, because alternative codes in different groups might have been used for the same operation. In these cases rates were calculated for ad hoc groups of similar individual operation codes. Thus, for example, the ad hoc group dental extraction (codes 251,252 ) overlaps with two standard groups: other operations on teeth (codes 252259) and drainage of abscess and dental extraction (codes 250, 251).

Admission rates were also calculated for all individual diagnoses using the three digit codes of ICD 9. A few three digit codes were aggregated into groups of similar diagnoses, for example, chronic bronchitis and emphysema (codes 490-2, 496). A list of common medical conditions was compiled by taking the 40 most common main diagnoses in patients admitted in the specialty of general medicine. Finally, rates were calculated for patients with particular combinations of operation and diagnosis; separating, for example, the removal of an organ for cancer from the same operation performed for other reasons.

There is space on the record of each hospital admission for up to six diagnoses and four operations. For admission rates based on ICD 9 diagnoses we analysed the data in two ways - firstly, counting only the main diagnosis and secondly counting all recorded diagnoses. In the same way rates were calculated separately for the operation designated the principal operation and for all recorded operations.

We report here on admission rates to all specialties (except psychiatry and obstetrics) for surgical procedures and common medical conditions. Results for cancers and trauma will be reported in more detail elsewhere. During the period covered by this study, most cardiac surgery for Oxford residents was provided out- 
side the Oxford region and is not therefore included in the analysis.

\section{Results}

In the study period, the ORLS included records of 1609588 hospital admissions. The SH3 returns from the hospitals, which are aggregated administrative statistics collected independently of the ORLS, recorded 1627237 episodes. The ORLS count was thus $98.9 \%$ of that given by $\mathrm{SH} 3$ (although the $\mathrm{SH} 3$ count cannot necessarily be regarded as the more accurate of the two). Codes for clinical diagnoses or operations, or both, were recorded on 1557753 of the ORLS records $(96 \cdot 8 \%)$.

\section{SURGICAL PROCEDURES}

Table 1 shows average annual standardised district rates, as multiples of the overall rate for the six districts combined, for 25 common operation groups. The level of variation differed appreciably for different procedures. Very little variation was observed in admission rates for operations such as prostatectomy, inguinal hernia repair, and cholecystectomy. For example, the lowest and highest admission rates for prostatectomy were $96 \%$ and $106 \%$ of the rate for the six districts combined (table 1). Differences of up to twofold were found for other operations such as myringotomy, hysterectomy, dilatation and curettage, and tonsillectomy. For example, the lowest and highest admission rates for tonsillectomy were $71 \%$ and $132 \%$ of the value for the six districts combined (table 1).

Table 2 shows the number of operation groups and proportion of surgical workload in each category of variability. Of the 118 standard operation groups, 80 had an SCV of less than
16 and accounted for $74 \%$ of all surgical procedures performed in the six districts. In the higher variation categories ( $\mathrm{SCV}=32$ or more) there were 19 operation groups, accounting for $17 \%$ of all procedures, including, for example, dilatation of the urethra $(\mathrm{SCV}=46 \cdot 7)$, plastic operations (51.3), vasectomy (133.7), and other surgical procedures $(77 \cdot 7)$. The full list of SCV values for all operation groups is available from the authors. In most cases counting people admitted rather than episodes of admission made very little difference to the level of variation for surgical procedures even for those operations which can be performed several times.

The results for combinations of diagnoses and procedures showed that rates for operations performed for cancer were less variable than rates for the same operations performed for other reasons. Examples of operations performed for people with and without cancer were gastrectomy ( $\mathrm{SCV}=2.7 \quad v \quad 11.1)$, colectomy $(0.7 v 2.2)$, and hysterectomy $(1.8 v$ $4 \cdot 8)$. Another example of the variability of a procedure depending on the indication for surgery was that of lower limb amputation. For this operation, district rates were more uniform for trauma than for peripheral arterial disease $(\mathrm{SCV}=0.4 v 5 \cdot 2)$.

\section{MEDICAL DIAGNOSES}

For some medical diagnoses (table 3) there was very little variation in either episode based or person based admission rates (for example, stroke, heart failure, diabetes, acute myocardial infarction, chronic bronchitis and emphysema). For other, mainly acute, conditions there was greater variation which was similar for episode based and person based admission

Table 1 Geographical variation in age standardised and sex standardised hospital admission rates: common surgical procedures

\begin{tabular}{|c|c|c|c|c|c|c|c|c|c|}
\hline \multirow[t]{2}{*}{ Operation group (OPCS III codes) } & \multicolumn{2}{|c|}{ Six districts combined } & \multicolumn{6}{|c|}{$\begin{array}{l}\text { Average annual standardised district admission rates* relative to the rate } \\
\text { for all six districts }\end{array}$} & \multirow[t]{2}{*}{ SCV† } \\
\hline & $\begin{array}{l}\text { Admission } \\
\text { episodes } \\
1979-86\end{array}$ & $\begin{array}{l}\text { Admissions per } \\
10000 \text { residents } \\
\text { per year }\end{array}$ & $\begin{array}{l}\text { District } \\
A\end{array}$ & $\begin{array}{l}\text { District } \\
B\end{array}$ & $\begin{array}{l}\text { District } \\
C\end{array}$ & $\begin{array}{l}\text { District } \\
D\end{array}$ & $\begin{array}{l}\text { District } \\
E\end{array}$ & $\begin{array}{l}\text { District } \\
F\end{array}$ & \\
\hline Prostatectomy (630-5) & 13161 & $7 \cdot 8$ & 1.02 & 1.06 & 0.97 & 0.96 & $1 \cdot 00$ & 0.96 & $0 \cdot 1$ \\
\hline Appendicectomy $(440-5)$ & 22474 & $13 \cdot 4$ & 0.92 & $1 \cdot 13$ & 1.03 & $1 \cdot 04$ & 0.96 & 0.92 & 0.7 \\
\hline Ops for fracture $(780-9)$ & 36525 & $21 \cdot 7$ & 1.01 & 0.98 & 0.99 & 1.01 & $1 \cdot 13$ & $0 \cdot 87$ & $0 \cdot 7$ \\
\hline Mastotomy and mastectomy (380-5) & 16885 & $10 \cdot 1$ & 1.03 & 0.91 & 1.00 & $0 \cdot 89$ & $1 \cdot 12$ & $1 \cdot 08$ & $0 \cdot 8$ \\
\hline Inguinal hernia repair $(410,411)$ & 23938 & $14 \cdot 2$ & $1 \cdot 04$ & $1 \cdot 11$ & 0.91 & 0.90 & 0.90 & $1 \cdot 08$ & $0 \cdot 9$ \\
\hline Ops on nerves $(032-49)$ & 11435 & $6 \cdot 8$ & 1.06 & 0.90 & $1 \cdot 10$ & $1 \cdot 10$ & $0 \cdot 88$ & 0.94 & $1 \cdot 0$ \\
\hline Circumscision and preputiotomy $(660,661)$ & 10234 & $6 \cdot 1$ & $1 \cdot 06$ & 1.03 & 0.95 & $0 \cdot 83$ & $1 \cdot 13$ & 0.93 & $1 \cdot 2$ \\
\hline Cholecystectomy (520-9) & 11962 & $7 \cdot 1$ & $1 \cdot 07$ & 1.05 & $0 \cdot 89$ & $0 \cdot 83$ & 1.06 & 1.07 & $1 \cdot 3$ \\
\hline Hip arthroplasty (810-14) & 13435 & $8 \cdot 0$ & $1 \cdot 11$ & $1 \cdot 17$ & 0.92 & 0.97 & 0.93 & 0.75 & $2 \cdot 5$ \\
\hline Ops on spine and spinal cord (021-9). & 11494 & $6 \cdot 8$ & $0 \cdot 83$ & $1 \cdot 18$ & $1 \cdot 14$ & $1 \cdot 12$ & $0 \cdot 78$ & $0 \cdot 95$ & $3 \cdot 0$ \\
\hline $\begin{array}{l}\text { Laparotomy and other ops. on abdominal } \\
\text { wall }(400-9)\end{array}$ & 31472 & $18 \cdot 7$ & $1 \cdot 00$ & $1 \cdot 32$ & 0.91 & $0 \cdot 81$ & $0 \cdot 84$ & $0 \cdot 98$ & $3 \cdot 1$ \\
\hline $\begin{array}{l}\text { Ops. on anal region, not haemorrhoidectomy } \\
(480-6,490,494-9)\end{array}$ & 16367 & $9 \cdot 7$ & 0.96 & 1.07 & 1.03 & $1 \cdot 32$ & $0 \cdot 78$ & $0 \cdot 82$ & $3 \cdot 6$ \\
\hline $\begin{array}{l}(480-0,490,494-9) \\
\text { Myringotomy }(193)\end{array}$ & 33692 & $20 \cdot 1$ & 0.97 & $1 \cdot 22$ & $0 \cdot 88$ & $1 \cdot 10$ & 1.05 & 0.70 & $3 \cdot 7$ \\
\hline Hysterectomy (690-6) & 21748 & 12.9 & $1 \cdot 07$ & $1 \cdot 17$ & 0.73 & 0.77 & $1 \cdot 14$ & 1.06 & $4 \cdot 3$ \\
\hline Cystoscopy and destruction of lesion (607-8) & 39929 & $23 \cdot 8$ & $1 \cdot 01$ & $1 \cdot 19$ & $1 \cdot 24$ & $0 \cdot 86$ & $0 \cdot 82$ & $0 \cdot 71$ & $4 \cdot 7$ \\
\hline Dilatation and curretage $(703,704)$ & 46862 & 27.9 & $0 \cdot 71$ & $1 \cdot 32$ & 1.08 & $0 \cdot 98$ & $0 \cdot 79$ & $1 \cdot 18$ & $5 \cdot 6$ \\
\hline Tonsillectomy and adenoidectomy (230-9) & 33959 & $20 \cdot 2$ & 0.71 & $1 \cdot 32$ & 1.01 & 0.79 & 0.95 & 1.29 & $6 \cdot 2$ \\
\hline Ops. on lens $(170-9)$ & 18571 & $11 \cdot 1$ & $1 \cdot 00$ & $1 \cdot 23$ & $1 \cdot 10$ & $0 \cdot 60$ & $1 \cdot 04$ & $0 \cdot 89$ & $6 \cdot 4$ \\
\hline Excision of superficial lesion $(912-4)$ & 19943 & $11 \cdot 9$ & 0.92 & $1 \cdot 16$ & 1.07 & $1 \cdot 26$ & 0.54 & 1.03 & $9 \cdot 1$ \\
\hline Ops. on veins $(890-8)$ & 15467 & $9 \cdot 2$ & 0.97 & $1 \cdot 21$ & 1.06 & $0 \cdot 84$ & 0.56 & $1 \cdot 30$ & $9 \cdot 3$ \\
\hline Haemorrhoidectomy (491-3) & 3887 & $2 \cdot 3$ & $1 \cdot 17$ & $1 \cdot 04$ & $1 \cdot 24$ & 0.64 & $0 \cdot 60$ & $1 \cdot 10$ & $10 \cdot 0$ \\
\hline Termination of pregnancy $(742)$ & 19768 & $11 \cdot 8$ & 1.59 & 0.91 & $0 \cdot 40$ & $0 \cdot 73$ & $1 \cdot 15$ & 0.89 & $21 \cdot 8$ \\
\hline $\begin{array}{l}\text { Anaesthesia or radiology with no operation } \\
(970-9,980-99)\end{array}$ & & 7.9 & 0.47 & $1 \cdot 20$ & $2 \cdot 22$ & $0 \cdot 74$ & $0 \cdot 49$ & $0 \cdot 89$ & $34 \cdot 3$ \\
\hline $\begin{array}{l}(970-9,980-99) \\
\text { Ops. on accessory air sinuses }(225-9)\end{array}$ & $\begin{array}{l}13242 \\
16795\end{array}$ & $10 \cdot 0$ & 0.50 & $2 \cdot 32$ & 0.89 & 0.80 & 0.43 & $0 \cdot 84$ & $35 \cdot 0$ \\
\hline $\begin{array}{l}\text { Ops. on stomach, not gastrectomy }(420 \text {, } \\
421,425-33,439)\end{array}$ & 27108 & $16 \cdot 1$ & 0.99 & $1 \cdot 02$ & $0 \cdot 73$ & $2 \cdot 47$ & 0.63 & $0 \cdot 19$ & $70 \cdot 8$ \\
\hline
\end{tabular}

*Episode based, the operation may appear anywhere on the record. $+\mathrm{SCV}=$ systematic component of variation. 
Table 2 Distribution of operation groups by category of variation

\begin{tabular}{lcc}
\hline $\begin{array}{l}\text { Category of } \\
\text { variation by } \\
\text { SCV* }\end{array}$ & $\begin{array}{l}\text { No of } \\
\text { operation } \\
\text { groups }\end{array}$ & $\begin{array}{l}\text { Proportion of } \\
\text { surgical } \\
\text { workload (\%) }\end{array}$ \\
\hline$<1$ & 6 & $10 \cdot 9$ \\
$1-$ & 9 & $6 \cdot 3$ \\
$2-$ & 25 & $18 \cdot 8$ \\
$4-$ & 24 & $25 \cdot 3$ \\
8 & 16 & $12 \cdot 4$ \\
$16-$ & 19 & $9 \cdot 7$ \\
$32-$ & 13 & $7 \cdot 4$ \\
$64+$ & 6 & $9 \cdot 2$ \\
Total & 118 & 100
\end{tabular}

*SCV = systematic component of variation, episode-based, all operations on each record.

rates (for example gastrointestinal haemorrhage, pneumococcal pneumonia, poisoning). This pattern suggests variation in the incidence of the condition or the threshood for admission but consistency in the proportion of patients who were admitted more than once. For other, mainly chronic, conditions the variation in episode based rates of admission was greater than it was for person based rates because of differences between districts in the rate of multiple admission for these conditions (for example, asthma, chronic renal failure, leukaemia, social admissions).

Of the 40 most common medical causes of admission, 36 had both episode based and person based SCV values which were less than 16. Of these, 18 had episode based SCV values and 23 had person based SCV values that were less than 4 . The full list of medical conditions and their SCVs is available from the authors.

INVESTIGATION OF POSSIBLE ARTEFACTUAL

CAUSES OF VARIATION

Residents of one district (D) seemed to have a lower admission rate than others for operations on the lens (table 1). The HIPE analysis showed that a much higher proportion of the residents of this district admitted for this operation were referred outside the ORLS area compared with residents of the other districts $(37 \% v 5 \%)$. There were very few other examples of large differences in rates of cross-boundary flow explaining interdistrict variation:

Rates calculated from counts of all operations performed during an admission were generally less variable than those based on the principal operation recorded, suggesting differences in the method used to designate and record the principal operation. For example, episode based admission rates for myringotomy as the first recorded operation had an SCV of 16.0 which fell to 3.7 when myringotomy was counted when recorded at any position on the record. Similarly, rates based on the selection of main diagnosis only on each record were more variable than those based on all recorded diagnoses.

Most of the ad hoc groupings of surgical procedures and medical diagnoses had much lower SCV values than equivalent standard groups or three digit ICD codes. For example, the ad hoc surgical group, female sterilisation (codes 684,687; SCV $=4 \cdot 7$ ), showed much less variation than the standard groups, division and ligation of oviducts (code 684; SCV = $116 \cdot 5)$, and other operations involving oviduct (codes 680-683, 685-689; SCV = 10.0), which includes bilateral endoscopic occlusion of oviducts.

The more vague or multi-purpose procedure categories and diagnoses tended to have high SCV values - for example, other surgical procedures (941-959; SCV $=77 \cdot 7$ ) and other operations on the stomach $(420,421,425-433$, 439; SCV $=70 \cdot 8$ ). It was known that, for a period, one district incorrectly used codes in this latter group for patients who underwent oesophagogastroscopies.

\section{Discussion}

Admission rates for surgical procedures are generally lower in this country than the USA, but it has been said that they are equally variable between geographically defined populations. ${ }^{371011}$ This view has tended to be based on research into a small number of conditions, using UK hospital activity data which can be of questionable quality, or

Table 3 Geographical variation in age standardised and sex standardised hospital admission rates (1979-86): common medical diagnoses

\begin{tabular}{|c|c|c|c|c|c|}
\hline \multirow[t]{2}{*}{$\begin{array}{l}\text { Diagnosis } \\
\text { (ICD-9 code) }\end{array}$} & \multirow[t]{2}{*}{$\begin{array}{l}\text { No of } \\
\text { admissions }\end{array}$} & \multicolumn{2}{|c|}{$\begin{array}{l}\text { Range of admission rates* } \\
\text { (Admissions per } 10000 \text { residents per year) }\end{array}$} & \multicolumn{2}{|l|}{ SCV† } \\
\hline & & Episodes & People & Episodes & People \\
\hline $\begin{array}{l}\text { Little variation: } \\
\text { Stroke }(431-4,436) \\
\text { Heart failure }(428) \\
\text { Diabetes mellitus }(250) \\
\text { Hypertension }(401) \\
\text { Acute myocardial infarction }(410) \\
\text { Epilepsy (345) } \\
\text { Chronic bronchitis and emphysema }(490-2,496)\end{array}$ & $\begin{array}{l}26535 \\
32979 \\
34826 \\
16699 \\
26796 \\
11269 \\
22750\end{array}$ & $\begin{array}{l}14 \cdot 3-17 \cdot 2 \\
17 \cdot 9-21 \cdot 7 \\
17 \cdot 2-24 \cdot 2 \\
7 \cdot 7-11 \cdot 1 \\
13 \cdot 5-20 \cdot 4 \\
5 \cdot 3-8 \cdot 1 \\
11 \cdot 3-15 \cdot 6\end{array}$ & $\begin{array}{c}12 \cdot 4-14 \cdot 9 \\
15 \cdot 3-18 \cdot 4 \\
13 \cdot 2-16 \cdot 7 \\
6 \cdot 8-9 \cdot 7 \\
12 \cdot 9-18 \cdot 9 \\
4 \cdot 2-6 \cdot 2 \\
9 \cdot 1-12 \cdot 0\end{array}$ & $\begin{array}{l}0 \cdot 6 \\
0 \cdot 4 \\
1 \cdot 5 \\
2 \cdot 0 \\
2 \cdot 1 \\
2 \cdot 4 \\
1 \cdot 3\end{array}$ & $\begin{array}{l}0.4 \\
0.5 \\
0 \cdot 8 \\
1.8 \\
1.9 \\
1.9 \\
0.9\end{array}$ \\
\hline $\begin{array}{l}\text { Variation in both episode based and person based rates: } \\
\text { Gastrointestinal haemorrhage }(578) \\
\text { Pneumococcal pneumonia }(481) \\
\text { Bronchopneumonia }(485) \\
\text { Pulmonary heart disease }(415-7) \\
\text { Poisoning }(960-79)\end{array}$ & $\begin{array}{r}6700 \\
4866 \\
18197 \\
9642 \\
30505\end{array}$ & $\begin{array}{c}2 \cdot 5-4 \cdot 6 \\
1 \cdot 9-3 \cdot 7 \\
6 \cdot 6-13 \cdot 6 \\
3 \cdot 2-13 \cdot 0 \\
13 \cdot 5-24 \cdot 4\end{array}$ & $\begin{array}{r}2 \cdot 2-3 \cdot 9 \\
1 \cdot 9-3 \cdot 4 \\
6 \cdot 0-13 \cdot 2 \\
2 \cdot 9-10 \cdot 8 \\
10 \cdot 5-18 \cdot 6\end{array}$ & $\begin{array}{r}4 \cdot 6 \\
6 \cdot 3 \\
7 \cdot 3 \\
18 \cdot 7 \\
4 \cdot 2\end{array}$ & $\begin{array}{r}4 \cdot 0 \\
5 \cdot 5 \\
8 \cdot 2 \\
17 \cdot 3 \\
4 \cdot 7\end{array}$ \\
\hline $\begin{array}{l}\text { Greater variation in episode based rates than person based rates: } \\
\text { Asthma (493) } \\
\text { Chronic renal failure }(585) \\
\text { Social admissions (V60) } \\
\text { Chronic liver disease }(571) \\
\text { Leukaemia }(204-8)\end{array}$ & $\begin{array}{r}23430 \\
7749 \\
42949 \\
3877 \\
5908\end{array}$ & $\begin{array}{c}11 \cdot 2-19 \cdot 1 \\
2 \cdot 5-6 \cdot 2 \\
8 \cdot 4-64 \cdot 5 \\
1 \cdot 6-3 \cdot 4 \\
2 \cdot 5-4 \cdot 4\end{array}$ & $\begin{array}{l}8 \cdot 5-12 \cdot 5 \\
1 \cdot 6-3 \cdot 0 \\
6 \cdot 1-12 \cdot 7 \\
1 \cdot 2-2 \cdot 1 \\
0 \cdot 7-1 \cdot 1\end{array}$ & $\begin{array}{r}5 \cdot 3 \\
9 \cdot 2 \\
52 \cdot 3 \\
7 \cdot 9 \\
5 \cdot 8\end{array}$ & $\begin{array}{l}2 \cdot 7 \\
5 \cdot 0 \\
6 \cdot 2 \\
4 \cdot 5 \\
2 \cdot 2\end{array}$ \\
\hline
\end{tabular}

* All diagnoses on each record.

† Systematic component of variation. 
studies of GP referral rates, which need to be interpreted carefully. ${ }^{1819}$ Authors of papers on variations rarely report in detail on the completeness of their data. Incompleteness and error, or even deliberate manipulation in the case of data used for reimbursement, ${ }^{20}$ will inflate the level of observed variation.

We have found that for many procedures and diagnoses the level of observed variation seems to be less in the Oxford region than that reported from elsewhere. Furthermore, some of the variation can be shown to be due to data artefacts such as cross boundary flows (for example, operations on lens) or inconsistent coding practice (for example, female sterilisation). Differences in the use of the private sector probably account for further variation in the rates of many elective operations (for example, vasectomy, female sterilisation, and termination of pregnancy), although this remains uncertain as little information is available on activity in private hospitals. Variation can also result from the use of alternative methods of treatment for a particular condition. ${ }^{21}$ For example, in one district (D) a treatment for haemorrhoids, Lord's procedure, ${ }^{22}$ was developed and widely used. The district had consistently low rates of haemorrhoidectomy and high rates for other operations on the anal region, the group which contains the code for dilatation of the anal sphincter (table 1).

It is difficult to know on a priori grounds whether a particular SCV value represents a high level of variation. One study attempted to define standards of variability on empirical grounds. Wennberg et al used data from Hospital Market Areas in Maine to define categories of variability from "low" to "very high" according to the $\mathrm{SCV}^{16}$; causes of admission were labelled "low variation" if the SCV was less than 22 . Only $1 \cdot 1 \%$ of admissions in Maine were for conditions in this category whereas in the Oxford region over $74 \%$ of surgical workload would have been in the "low variation" category. In the UK, it has been suggested (without any specific justification) that an SCV of less than 4 represents low variation, and above 10 high variation. ${ }^{23}$ The results in table 2 provide evidence to support the use of this standard in the UK as about a third of surgical workload would be in each of these categories.

Studies that have included medical diagnoses have found even wider ranges of admission rates than for surgical procedures. ${ }^{57}$ Wennberg et al classified medical and surgical admissions in Maine into 111 modified diagnostic related groups. ${ }^{16}$ They found that only three medical groups (acute myocardial infarction, gastrointestinal haemorrhage, and specific cerebrovascular disorders) were less variable than hysterectomy, and no medical groups were in the "low variation" category $(\mathrm{SCV}<22)$. In our study, most of the 40 common general medical conditions had an SCV of less than 16 and would therefore have been considered "low variation" causes of admission in the USA. For 19 of them, episode based admission rates were less variable than hysterectomy rates in Oxford $(\mathrm{SCV}=4 \cdot 3)$.

We are not aware of any published research on geographical variation in admission rates based on numbers of people admitted rather than numbers of episodes of admission. Variation in multiple admission ratios ${ }^{24}$ (the number of episodes per person admitted) was an important component of overall variation for a number of medical causes of admission. It accounted for half of the variation in admission rates for asthma and chronic renal failure, and for over $80 \%$ of the variation in social admissions and admissions for multiple sclerosis. Highly variable multiple admission ratios, if not due to artefact, strongly suggest differences in the way these conditions are managed and should, therefore, be investigated further.

The reasons for variation in recorded admission rates have been well described. ${ }^{25} \mathrm{~A}$ number of factors could explain the smaller differences in admission rates in the Oxford region compared with studies from the USA. One of the most important of these is likely to be the supply of resources used for health care, which would be much more similar (and probably more equitable) between districts in an English region than between Hospital Market Areas in the USA. Financial constraints in the NHS probably limit workload to the more severe end of the clinical spectrum for some conditions, compared with the USA, and so the scope for variation resulting from other supply factors is reduced. For example, the number of surgeons available locally has less of an effect on operation rates in the UK than in the USA. ${ }^{25}$ Our results suggest that when the supply of hospital resources is controlled but clinical autonomy is preserved, as has been the case in the Oxford region and elsewhere in the NHS, variation on the scale that is common in the US (SCV>22) is seen for a much smaller proportion of total workload than would otherwise be the case.

Because of their proximity to each other, the amount of variation seen between the six districts in this study probably underestimates the extent of variation in the NHS as a whole. Doctors working in the same region may share a common clinical approach which leads them to make similar use of hospital beds. On the other hand, the difference between the national and the local situation may not be that great. Each district was served by its own general hospital and the clinicians working in them practised with substantial clinical autonomy. This autonomy is demonstrated by the fact that procedures for which the indications are known to be poorly defined (for example, tonsillectomy, and dilatation and curettage) showed relatively high variability in our study as has been found elsewhere. Furthermore, although not encompassing the social spectrum of the whole country, the populations of the six districts are socially and economically dissimilar. These differences are reflected in objective differences in health status. For example, during the period of this study there were twofold differences between districts in lung cancer mortality in men under 75 years, and coronary heart disease mortality differed by $40 \%$ in men under 65 years.

Although differences in admission rates in 
the Oxford region were generally smaller than those found in the USA, and smaller than some of those reported by others in the UK, some were substantial and require explanation. Also, where there is little variation in admission rates there could be important differences in the mode of treatment (for example, in the use of minimally invasive techniques). After the introduction of the NHS and Community Care Act (1990) the purchasers of hospital care are unlikely to continue to fund procedure rates above regional or national norms without persuasive arguments for doing so. Unfortunately, in some cases, moving towards the norm could lead to a reduced quality of service. Where variation is identified, the problem remains of whether a high, low, or intermediate rate is appropriate. This dilemma shows the need for a better understanding of the epidemiology of the indications for treatment ${ }^{26}$ and the effectiveness of that treatment. ${ }^{2728}$ In order to guide this work, reliable data on admission rates, comparing suitable geographically defined populations for specific conditions, should be available as a routine part of monitoring the provision of hospital care.

The Unit of Health-Care Epidemiology is funded by the Department of Health and also receives support from the Oxford Regional Health Authority. This study was funded as part of the Department of Health's grant reference number 121/2584. We thank Leicester Gill, Hugh Simmons, and David Yeates for computing support.

1 Glover JA. The incidence of tonsillectomy in school children. Proc Roy Soc Med 1938;31:1219-36.

2 Pearson RJC, Smedby B, Berfenstam R, Logan RFL, Bur-

gess AM, Peterson OL. Hospital caseloads in Liverpool, gess AM, Peterson OL. Hospital caseloads in Liverpool, New England and Uppsat
Lancet 1968;ii:559-66.

3 McPherson K, Wennberg JE, Hovind OB, Clifford P. Smallarea variations in the use of common surgical procedures: an international comparison of New England, England and Norway. $N$ Engl f $\mathrm{Med}$ 1982;307:1310-14.

4 Black N. Geographical variations in use of surgery for glue ear. $f R$ Soc Med 1985;78:641-8.

5 Paul-Shaheen P, Clark JD, Williams D. Small area analysis: a review and analysis of the north American literature. $f$ Health Polit Policy Law 1987;12:741-809.
6 Jessop EG. Equity of access? Small area variations in surgery. Community Medicine 1988;10:1-7.

7 Sanders D, Coulter A, McPherson K. Variations in hospital admission rates: a review of the literature. London: King's Fund, 1989

8 Price CE, Paul EA, Bevan RG, Holland WW. Equity and medical practice variation: relationships between standmedical practice variation: relationships between standardised discharge ratios in total and for selected conditions
in English districts. $\mathcal{F}$ Epidemiol Community Health 1992; in English

9 Wennberg JE. Population illness rates do not explain population hospitalization rates. Med Care 1987;25:354-9.

10 Bunker JP. Variations in hospital admissions and the ap propriateness of care: American preocccupations? $B M \mathcal{F}$ 1990;301:531-2.

11 Wennberg JE, Barnes BA, Zubkoff M. Professional uncertainty and the problem of supplier-induced demand Soc Sci Med 1982;16:811-24.

12 Klein R. The American health care predicament: spending more feeling worse. BMF 1991;303:259-6G

13 LoGerfo JP. Organisational and financial influences on patterns of surgical care. Surg Clin N Am 1982;62:677-84.

$14 \mathrm{McPherson} \mathrm{K}$. Variations in hospitalisation rates: why and how to study them. In: Ham C, ed. Health care variations: assessing the evidence. London: Kings Fund Institute, 1988: $15-20$.

15 World Health Organisation. International classification of diseases, 9th Rev: Geneva: WHO, 1977.

16 Wennberg JE, McPherson K, Caper P. Will payment based on diagnosis-related groups control hospital costs? $N$ Engl on diagnosis-related group

17 Office of Population Censuses and Surveys. Classification of surgical operations. Third revision. London: OPCS, 1975.

18 Crombie DL, Cross KW, Fleming DM. The problem of diagnostic variability in general practice. $\mathcal{f}$ Epidemiol Community Health 1992;46:447-54.

19 Moore AT, Roland MO. How much variation in referral rates among general practitioners is due to chance? $B M Y$ 1989;298:500-2.

20 Simborg DW. DRG creep: a new hospital-acquired disease. N Engl f Med 1981;304:1602-4.

21 Moore FD. Small-area variations studies: illuminating or misleading? Health Affairs 1985;4:96 101.

22 Lord PH. A day-case procedure for the cure of third-degree haemorrhoids. Br 7 Surg 1969;56:747-9.

23 Black N, Langham S, Petticrew M. Cornary artery bypass grafting and coronary angioplasty: access to and availability grafting and coronary angioplasty: access to and availability
of specialist services. Report of a Clinical Standards Advisory Gmup working group. London: HMSO, 1993.

24 Newton J, Goldacre M. Multiple hospital admissions in a calendar year. I Public Health Med 1993;15:249-54

25 McPherson K, Strong PM, Epstein A, Jones L. Regional variations in the use of common surgical procedures: within and between England and Wales, Canada and the United States of America. Soc Sci Med 1981;15A:273-88

26 Frankel S. The epidemiology of indications. I Epidemiol Community Health 1991;45:257-9.

27 Wennberg JE. Outcomes research, cost containment, and the fear of health care rationing. $N$ Engl F Med 1990;323 $1202-4$.

28 Evidence-Based Medicine Working Group. Evidence-based medicine: a new approach to teaching the practice of medicine. $7 A M A$ 1992;268:2420-5. 